\title{
Editorial
}

\section{Más allá de la globalización... Las mayorías populares, sujetos y no actores}

Nuestras reacciones ante la denominada globalización, mucho dependerán de cómo la entendamos, o inclusive, de si no la entendemos. Cuando algunos políticos o gobernantes nuestros, por ejemplo, plantean que "la globalización es un fenómeno de indiscutible realidad", sugieren entenderla, pero cuando a continuación agregan: "y por tanto es ineludible nuestra incorporación a la misma", nos percatamos de que no comprenden a profundidad todas sus implicaciones, en tanto que pareciera que estos políticos están convencidos que para ser parte de esa realidad, bastaría con saber aprovechar las oportunidades que se nos brinda, algo así como si se tratara simplemente de "subirse" en el último vagón del tren de la globalización. Sin embargo, la globalización económica esta muy lejos de parecerse a un tren o un autobús de parada obligatoria, más bien, podría compararse metafóricamente con un globo donde solo tienen cabida aquellas personas o entidades que tienen un vínculo con las empresas transnacionales, quien de suyo, son las responsables directas de este proceso.

Por nuestra parte entendemos la globalización neoliberal como el resultado de la $4^{\mathrm{a}}$. Internacionalización del capital, la cual se caracteriza por la mundialización del mismo, bajo sus tres formas básicas: la del capital industrial, el comercial y el financiero. El proceso actual tiene de común con los anteriores, la tendencia a la internacionalización del capital, aunque en el pasado dominaba una tan sola forma. Así la primera internacionalización correspondió al capital industrial, la segunda al comercial y la tercera al financiero; en cambio en su 
cuarta internacionalización son las tres formas las que se globalizan y se presentan, como es lógico con sus propias características.

Así tenemos que la globalización del capital industrial se caracteriza por la fragmentación y dislocación del proceso de trabajo, lo cual lleva a que el capital industrial ubique en cualquier lugar del mundo partes del proceso de producción, atendiendo a los viejos criterios de minimizar costos y maximizar beneficios, lo cual ha llevado a que también los productos — como el capital - ya no posean nacionalidad. La Nissan ya no dice hecho en Japón, sino made in Nissan. Porque ocurre que las distintas partes de sus vehículos han sido fabricadas en distintos lugares del mundo.

Igual se ha globalizado el capital comercial y ello se hace evidente en la universalización de los gustos, de la diversión, de los mercados, de la cultura y, obviamente, de los productos, todo lo cual asegura una demanda global para los productos de las empresas transnacionales.

Y en cuanto al capital financiero, encontramos que gracias a la revolución de las tecnologías de la información, este ha alcanzado una movilidad sin precedentes, posibilitando la realización de grandes negocios, así como prácticas especulativas impensables en el pasado.

Sin embargo, no se ha responsabilizado a las empresas transnacionales de las severas crisis que han provocado en el ámbito mundial y de las consecuencias sociales, económicas y políticas que esto representa para los países pobres. Por el contrario, se nos hace creer que estas situaciones se deben a que aún persisten "distorsiones en el mercado", y que las mismas son superables desde el punto de vista técnico, a través de la aplicación de unos mecanismos de regulación que tiendan a frenar la excesiva movilidad del capital financiero. No obstante, este discurso ideológico, evade la responsabilidad ética y esconde el trasfondo político. que protege los intereses de las grandes empresas transnacionales. Indiscutiblemente queda claro que por encima de la dignidad del ser humano y de los pueblos se impone el criterio de profundizar la concentración del capital, o de manera más general, la riqueza y como consecuencia de ello, se incrementa la pobreza y la marginación social como nunca antes en la historia de la humanidad.

Es obvio que si concebimos a la globalización en los términos anteriores y si además tenemos en cuenta que los sujetos de la misma, son las empresas transnacionales, las cuales, poseen más poder económico que muchísimos estados nacionales, resulta poco serio el pretender regular la globalización o soñar con una globalización que fuese democrática, incluyente y sustentable. La globalización es lo que es y genera lo que genera por su naturaleza capitalista y no por mala voluntad de sus agentes o por su carácter global. De la globalización se destaca como diferente, el hecho de que los fenómenos, así como sus consecuencias o efectos son también globales. 
Sin embargo, en la periferia de esta tendencia dominante existen conglomerados de seres humanos que desde su situación de marginados y excluidos han tenido que implementar estrategias de sobrevivencia y desarrollo. De hecho y a diferencia de lo que sostienen en sus discursos algunos políticos y tecnócratas, en el país existen propuestas alternativas que cuestionan los efectos no deseados de la globalización neoliberal desde las perspectivas etico-social, económica o ambiental. Lo interesante de estos planteamientos es que por una parte develan las debilidades y contradicciones de este proceso globalizador y, por otra parte, los resultados de estas experiencias aportan elementos para realizar un análisis radical de sus principales fundamentos.

En este sentido, es importante señalar algunos supuestos fundamentales que sustentan estos nuevos planteamientos. En primer lugar, debemos destacar que aunque se hable de globalización, como si esta existiera en sentido absoluto, en la realidad ésta se presenta como una tendencia, lo cual deja espacios reales para que ocurran otros procesos al margen o independientes de la globalización capitalista. En segundo lugar, en la búsqueda de propuestas alternativas y viables, nos parece que debe de regir el principio metodológico siguiente: los tradicionalmente considerados como objetos de la investigación social son en realidad los sujetos. De lo cual se deriva un tercer hecho, cual es que antes de elaborar propuestas especulativas que busquen convertir a los sujetos en actores de las propuestas, es preciso investigar, conocer y sistematizar lo que los sujetos reales están haciendo para enfrentar sus problemas y consecuentemente, darles solución. $\mathrm{O}$ sea, pues, que se reconoce y se insiste en la participación y el protagonismo de los sujetos reales o históricos.

Para el caso de El Salvador, existen varias investigaciones que informan sobre experiencias alternativas entorno al Desarrollo Económico Comunitario de aquellos sectores de la sociedad rural y urbana en condiciones de pobreza, desempleo o bajos ingresos. Contrario a lo que pudiesen creer los "expertos", lo importante aquí es el protagonismo de estos sectores, quienes han optado por enfrentar sus problemas de manera organizada y ya no depender de la asistencia paternalista, nociva para la auto-estima y para el desarrollo personal y social.

Sin contar con el reconocimiento oficial del gobierno central y de los gobiernos municipales, estas iniciativas han demostrado su potencial innovador $y$ su capacidad para deconstruir aquellas unidades económicas y ajustarlas de acuerdo a sus necesidades básicas. Efectivamente, la existencia de un vasto cúmulo de experiencias en el ámbito de la producción, del comercio y de los servicios, evidencia el dinamismo social que se dan en su interior y, lo que es mejor aún, demuestran su potencial en cuanto a su capacidad organizativa y en relación con la recuperación de valores tan importantes como lo es la cooperación, la equidad, la solidaridad, la unidad y la participación ciudadana. Valores que seguramente están creando las bases para una nueva cultura popular, la cual ya tiene 
múltiples manifestaciones artísticas: en poesía, canto y danza dentro de las comunidades rurales. No obstante y sin afán de idealizar estas experiencias, también es necesario decir que adolecen de problemas sociales que a su vez amenazan estos logros, como cualquier otro sector social del país.

Si los organismos internacionales, los gobiernos y las ONGs entendieran y asumieran - como algunos ya lo han hecho- que ayudar a los pobres a que por si mismos resuelvan sus problemas es la mejor forma de ayuda que se les puede dar, seguramente que estariamos entrando al nuevo siglo con muchas esperanzas.

Decimos lo anterior porque la experiencia nos muestra que la mejor forma de enfrentar la pobreza y la marginación social, es aquella encontrada por los propios sectores pobres y marginados, cuando actúan de manera organizada.

Dadas las limitaciones de este espacio basta con señalar algunos ejemplos que ilustren tal aseveración: primero, las condiciones de vida y de trabajo en las comunidades de repobladores y repatriados, son mejores que las condiciones medias de los campesinos no organizados; segundo, la mayoría de familias de este sector organizado, son propietarios de la tierra y las viviendas, lo cual les ha modificado sus actitudes y modos de relacionarse con la naturaleza; tercero, los costos sociales de implementar programas -de cualquier tipo- en comunidades organizadas se reducen significativamente y se gana en efectividad. $Y$ finalmente, quiero mencionar que ante las inundaciones dejadas por el reciente temporal las comunidades del Bajo Lempa, lo primero que hicieron fue crear comisiones de seguridad, de disciplina, de salud, de abastecimiento, etc. Ciertamente, no son inmunes a las desgracias naturales, pero por su alto nivel organizativo, los efectos y consecuencias que se derivan de los mismos, les habrán afectado en menor medida, en tanto cuentan con una mayor capacidad de reconstrucción y de recuperación.

Excluidos y marginados de la globalización económica, asumidos estadísticamente como problemas y abordados como objetos de tantas iniciativas -en su mayoría infructuosas- públicas y privadas, estos sectores mayoritarios se están convirtiendo en los sujetos de aquellos planteamientos que cuestionan el determinismo de la mundialización económica, en tanto han sido capaces de impulsar - por supuesto en su nivel- experiencias exitosas para generar ingresos y satisfacer necesidades. Por supuesto, hace falta mucho camino por andar, pero como un signo esperanzador, nos revelan que más allá de los intereses del capitalismo salvaje, existen alternativas que pueden devolverle la dignidad a la vida humana. 